\title{
Effect of Ground and Pelleted Sericea Lespedeza Whole Plant and Leaf Only on Gastrointestinal Nematode and Coccidial Infection in Goats
}

\author{
Gregory Dykes ${ }^{1}$, Thomas Terrill ${ }^{1}$, Niki Whitley ${ }^{1}$, Anil Singh ${ }^{1}$, Jorge Mosjidis ${ }^{2}$, Joan Burke ${ }^{3}$ and James Miller ${ }^{4}$ \\ 1. Fort Valley State University, Fort Valley, GA 31030, USA \\ 2. Auburn University, Auburn, AL 36849, USA \\ 3. United States Department of Agriculture, Agricultural Research Service, Booneville, AR 72927, USA \\ 4. Louisiana State University, Baton Rouge, LA 70803, USA
}

\begin{abstract}
Two 42-day feeding trials in pens were completed with young goats (Spanish, intact male, six months old, $n=29$ Trial 1; $n=20$ Trial 2) to determine the anti-parasitic bioactivity of whole plant and leaf only sericea lespedeza (SL; Lespedeza cuneata) fed as a ground meal or in pelleted form. In Trial 1, goats were fed SL leaf only pellets, SL whole plant pellets, or a commercial goat pellet as $50 \%$ of a complete ration, while in Trial 2, kids were fed either ground SL leaf meal or ground whole plant SL meal as $25 \%$ of a complete ration. Fecal samples were collected weekly for determination of gastrointestinal nematode (GIN) fecal egg counts (FEC) and coccidia fecal oocyst counts (FOC). In Trial 1 , both of the pelleted SL rations reduced FEC $(p<0.06)$ relative to the kids fed the control ration, and for FOC, there were lower values on Days 7 to 42 relative to Day 0 for goats on either pelleted SL diet, while FOC for control animals did not change over time (interaction, $p<0.01$ ). In Trial 2, both ground whole plant and leaf only SL diets reduced $(p<0.05)$ FEC of the goats over time, but the effect was faster in the kids on the SL leaf meal ration. At 50\% of the diet, SL leaf and whole plant meal pellets were equally effective against GIN egg and coccidial oocyst production in young kids, but SL leaf meal was more effective in reducing GIN egg production than whole plant SL meal when fed at 25\% of the diet.
\end{abstract}

Key words: Coccidia, gastrointestinal nematodes, goats, pellets, sericea lespedeza.

\section{Introduction}

Infection with gastrointestinal nematodes (GIN), coccidia (Eimeria spp.), and other internal parasites are a major factor causing a decrease in the productivity of livestock worldwide, especially in grazing small ruminants, such as goats and sheep [1, 2]. Poor growth rate, reduced reproductive capacity and increased mortality of heavily infected animals increases costs and reduces sustainability of small ruminant production systems world-wide [3, 4]. In tropical and subtropical regions, as well as much of the United States during the warmer months, there is a high prevalence of infective pastures due to a

Corresponding author: Thomas Terrill, professor, research field: animal science. favorable environment for the free-living life stages (eggs and larvae) of parasites to survive and grow [5]. Haemonchus contortus, the infamous "barberpole worm”, a dangerous blood-feeder, is the most prevalent and pathogenic GIN in sheep and goats, causing severe anemia and even death in untreated animals [3]. Use of broad-spectrum anthelminitcs has been the primary defense against GIN infections in livestock over the past 60 years, but the overuse and misuse of these drugs has led to a greatly increased prevalence of anthelmintic resistance among the major nematode species [6, 7]. In addition, poor availability and affordability of synthetic anthelmintics for resource-poor farmers have exacerbated the challenge of parasite management in many parts of the world [8]. 
In addition to GIN, infection with Eimeria spp. (coccidia) can have devastating consequences for young animals (kids and lambs), particularly during times of stress, such as at weaning [9]. Resistance to commercial coccidiostats is also a growing problem, particularly in the poultry industry $[10,11]$.

The rapidly increasing prevalence of drug resistance in livestock parasites is now reaching epidemic proportions [12] and has greatly increased pressure to develop and validate novel methods of parasite management that are less reliant on chemotherapeutics. Examples of these include feeding copper oxide wire particles, use of nematode trapping fungi, and grazing or feeding of anti-parasitic plants [13].

Condensed tannins (CT) in some plant species have been recognized as having anthelmintic properties, but until fairly recently, little research had been done to validate these plants (vegetative legumes, shrub species, legume trees) as livestock feed. There have been a number of reports documenting reduction in GIN infection in sheep and goats fed CT-containing forages, including sulla (Hedysarum coronarium L.) [14, 15], birdsfoot trefoil (Lotus corniculatus L.) [15], big trefoil (L. pedunculatus Cav.) [16], and sainfoin (Onobrychis viciifolia Scop.) [17]. As each of these is cool-season vegetative legumes, they are generally poorly adapted to warmer regions of the Southeastern United States. Research on anti-parasitic plants in this region has focused mainly on sericea lespedeza (SL; Lespedeza cuneata (Dum.-Cours. G. Don)), a high CT, low-input, warm-season perennial legume well adapted to acidic, infertile soils in the South [18].

In addition to its use as pasture, hay, and a conservation plant in the Southeast [19], there is recent documentation of bioactive properties of SL. Examples of SL bioactivity include reduction of ruminal methane in livestock [20, 21], increased rumen protein bypass [22], and suppression of house flies, Musca domestica, in feces [23]. Of particular interest is SL control of Eimeria spp. [24, 25] and $H$. contortus as well as other GIN in both sheep and goats
[26-28]. The parasitic inhibition bioactivity of SL has been attributed to the unique type of CT in this forage (up to $98 \%$ prodelphinidin-type tannins) [25, 29]. These anthelmintic properties have been documented in both fresh (grazed) [29, 30] and dried (hay, leaf meal, pellets) $[13,28]$ forms of SL. The dried forms of SL have been included in feeding trials with both sheep and goats using unground (long) and ground SL hay [13, 26], leaf meal [31, 32], and whole plant and leaf only pellets fed as the primary diet $[25,28]$ or leaf only pellets fed as a supplement on grass pasture [33].

One area of SL bioactivity with little documented research is possible differences in nutritional and anti-parasitic properties of SL leaves only compared to whole plant SL. Older SL literature showed that CT levels are much higher in leaves than stems [34], and recent work has shown that the CT in SL leaves and stems also differs in their molecular structure, with leaf CT being much larger in size than stem CT (polymers of larger mean degrees of polymerization; 42 vs. 18, respectively) and slightly higher concentration of prodelphinidin tannins (98\% vs. $94 \%$, respectively) [29]. With higher levels of crude protein (CP) as well as CT in SL leaves [34], the ratio of SL leaf to stem material in feed rations may influence the nutritional value and bioactivity of this forage. The specific objective of the current investigation was to evaluate possible differences in anti-parasitic bioactivity of dried SL whole plant (SLWP) (leaves + stems) compared to leaves only, both in ground (meal) and pelleted forms when fed to young goats.

\section{Materials and Methods}

All procedures completed in this investigation were approved by the Institutional Animal Care and Use Committee (IACUC) at Fort Valley State University (FVSU). The study consisted of two confinement feeding trials conducted at the FVSU Agricultural Research Station in Fort Valley, GA. At the end of both trials, goats were harvested through the FVSU abattoir under federal inspection, with adult worms 
recovered from the abomasum from each animal for counting and identification to species as described by Shaik et al. [26].

\subsection{Trial 1}

Twenty-seven naturally parasite infected 6-month-old intact male Spanish kids (34.1 $\pm 7.0 \mathrm{~kg}$ ) were fed in individual pens with packed dirt floors and mulch bedding. Diets consisted of SL pellets made from ground whole plant (SLWP) or leaf meal (SLM), or a commercial pellet (control; CON) at $50 \%$ of a complete ration (Table 1), with the remaining 50\% made up of ground corn (83.3\%), soybean meal (12.7\%), trace mineralized salt (2.0\%), and vitamin premix (2.0\%). The rations were fed for $42 \mathrm{~d}$ at $3.5 \%$ of body weight with daily adjustments to allow for approximately $10 \%$ orts. Animals were provided ad libitum access to fresh water daily in buckets. Body weights were collected at the start and end of the trial, and blood and fecal samples were collected from individual animals every $7 \mathrm{~d}$ throughout the study, beginning on Day 0 (first day of treatment).

\subsection{Trial 2}

For the second trial, 20 naturally GIN-infected six months old intact male goats were fed ground SL hay (whole plant or leaf only) as $25 \%$ of a complete ration in pens with 5 goats/pen and 2 pens/treatment for $42 \mathrm{~d}$. The treatment rations were balanced for protein and energy using ground corn, soybean meal and dry molasses. Animals were provided with ad libitum access to the assigned feed ration and water. Goat GIN infection was boosted by giving each animal $500 \mathrm{H}$. contortus larvae three times per week throughout the trial. Fecal and blood samples were collected from individual animals every $7 \mathrm{~d}$ beginning at Day 0 (first day of treatment).

\subsection{Analyses}

\subsubsection{Blood Samples}

For each trial, blood samples were collected from individual animals by jugular venipuncture into $3 \mathrm{~mL}$ purple top BD Vacutainer ${ }^{\circledR}$ tubes containing $\mathrm{K}_{2}$ EDTA, placed on ice for transfer to the laboratory, and placed on a tube rocker until processed. For each sample, micro-hematocrit capillary tubes were filled with whole blood, sealed, and then centrifuged for $10 \mathrm{~min}$ at $10,000 \times \mathrm{g}$ in a hematocrit centrifuge (IEC Model Mb, Needham Heights, MA). After centrifugation, the tubes were removed and percentage packed cell volume (PCV) values read using a hematocrit reader.

\subsubsection{Fecal Samples}

Using a gloved finger technique, fecal samples were collected directly from rectum of all animals during each trial for determination of fecal egg count (FEC), and for Trial 1, fecal oocyst count (FOC), using the modified McMaster technique [35]. Results were expressed as eggs per gram (epg) or oocysts per gram (opg) of feces.

\subsubsection{Recovery and Counting of Adult Nematodes}

During harvest of the animals at the FVSU abattoir, as described by Shaik et al. [26], the abomasum of each animal was ligated and removed, with the contents washed into plastic buckets and brought up to

Table 1 Chemical composition of sericea lespedeza (SL) ground meal and pellets (all values expressed on dry matter basis).

\begin{tabular}{llll}
\hline Forage type & \multicolumn{3}{c}{ Constituent } \\
\cline { 2 - 4 } & CP $\%$ & NDF \% & ADF \% \\
\hline SLWP & 12.7 & 41.9 & 40.0 \\
SLM & 17.6 & 36.6 & 25.3 \\
SLWP pellet & 14.6 & 41.9 & 42.7 \\
SLM pellet & 14.7 & 49.3 & 37.1 \\
Commercial pellet & 16.0 & NA & NA
\end{tabular}

SLWP = sericea lespedeza whole plant; SLM = sericea lespedeza leaf meal; CP = crude protein; NDF = neutral detergent fiber; ADF = acid detergent fiber; NA = data not available. 
$3 \mathrm{~L}$ with tap water. Aliquots $(5 \%, 150 \mathrm{~mL})$ were collected and placed into $250 \mathrm{~mL}$ storage containers, with $100 \mathrm{~mL}$ of formalin (10\%) added to each aliquot as a preservative. The adult nematodes in the samples were processed and then counted and identified to species and sex using a stereoscope microscope (Leica Zoom 2000, Leica Microsystems Inc., Chicago, IL) with total adult nematodes in the abomasum calculated as number of worms counted in each $5 \%$ aliquot $\times 20$.

\subsection{Statistical Analyses}

FEC, FOC and blood PCV data were analyzed using a linear mixed model for repeated measures in a completely randomized design using SAS 9.4, TS1M3 MIXED [36]. Adult GIN were analyzed as a completely randomized design using the general linear model (GLM) procedure of SAS [36]. The FEC, FOC, and PCV data were log-transformed prior to statistical analysis $(\log (\mathrm{FEC}+25), \log (\mathrm{FOC}+25) ; \log (\mathrm{PCV}+$ 1)) and reported as least squares means, with statistical inferences based upon log-transformed data analysis. For significance levels, $p$-values of $<0.05$ were considered significant and a tendency was noted at $p<0.10$.

\section{Results}

3.1 Trial 1-SL Leaf and Whole Plant Pellets at 50\% of the Diet

\subsubsection{FEC}

FECs were impacted by treatment $(p<0.01)$ in which SLM and SLWP fed goats had lower $(p<0.01$ for SLM, $p=0.0564$ for SLWP pellets) FEC than those goats fed the CON diet (Fig. 1). The FECs were also impacted by day $(p<0.001)$ and were highly variable, with Day 0 differing from Days 7, 28 and $35(p<0.02)$, Day 7 also differing from Days 14 and $21(p<0.02)$, and Days 14 and 21 also differing from Days 28, 35 and $42(p<0.04)$. Average FECs were 2,131 \pm 319 , $1,087 \pm 319,2,379 \pm 323,2,018 \pm 323,1,224 \pm 336$,
$1,440 \pm 329$ and 2,094 \pm 319 epg for Days 0, 7, 14, 21, 28,35 and 42 , respectively.

\subsubsection{FOC}

There was a treatment $\times$ day interaction $(p<0.02)$ for FOC (Fig. 2). Compared to Day 0, FOCs were lower at all other time points measured for goats fed SLM pellets or SLWP pellets ( $p<0.01$ ), but were not different over time for CON fed kids. When treatments were compared within days, there were no differences on Day 0, but FOCs of the kids were lower $(p<0.03)$ relative to control for the SLWP fed goats and tended to be lower $(p<0.07)$ in the animals on the SLM diet on Day 7. The FOC values were lower $(p<0.05)$ in goats fed the SLM compared to the CON diet on Days 14, 21, 28, 35 and 42, while the SLWP fed goats were more variable, with lower FOC than CON on Days 14 $(p<0.009)$ and $35(p<0.001)$ only.

\subsubsection{PCV}

Percentage PCV was not impacted by treatment, but was influenced by day $(p<0.001)$, with Day 21 values being higher $(p<0.01)$ than those on Days 7, 14 and 42, and Day 28 values being higher $(p<0.01)$ than those from Days 14 and 42. Values averaged 21.4\%, 20.6\%, $20.2 \%, 23.5 \%, 23.0 \%$ and $19.7 \%($ SEM $=1.0 \%)$ for Days 0, 7, 14, 21, 28 and 42, respectively. Data were not available for Day 35.

3.1.4 Adult Worm Number and Body Weights

There were no treatment differences for number of adult abomasal GIN, which consisted of predominantly $H$. contortus (87.3\%), with the remainder identified as Trichostrongylus axei (Table 2). Body weights on Days 0 and 42 as well as average daily gain were not impacted by treatment, averaging $34.2 \pm 1.3 \mathrm{~kg}, 34.5 \pm 1.2 \mathrm{~kg}$ and $7.6 \pm 14.2$ g/d, respectively.

\subsection{Trial 2-SL Leaf and Whole Plant Ground Meal as} $25 \%$ of the Diet

\subsubsection{FEC}

There was a treatment $\times$ time interaction $(p<0.007)$ in FEC goats fed SLM or SLWP meal for $42 \mathrm{~d}$ (Fig. 3). 

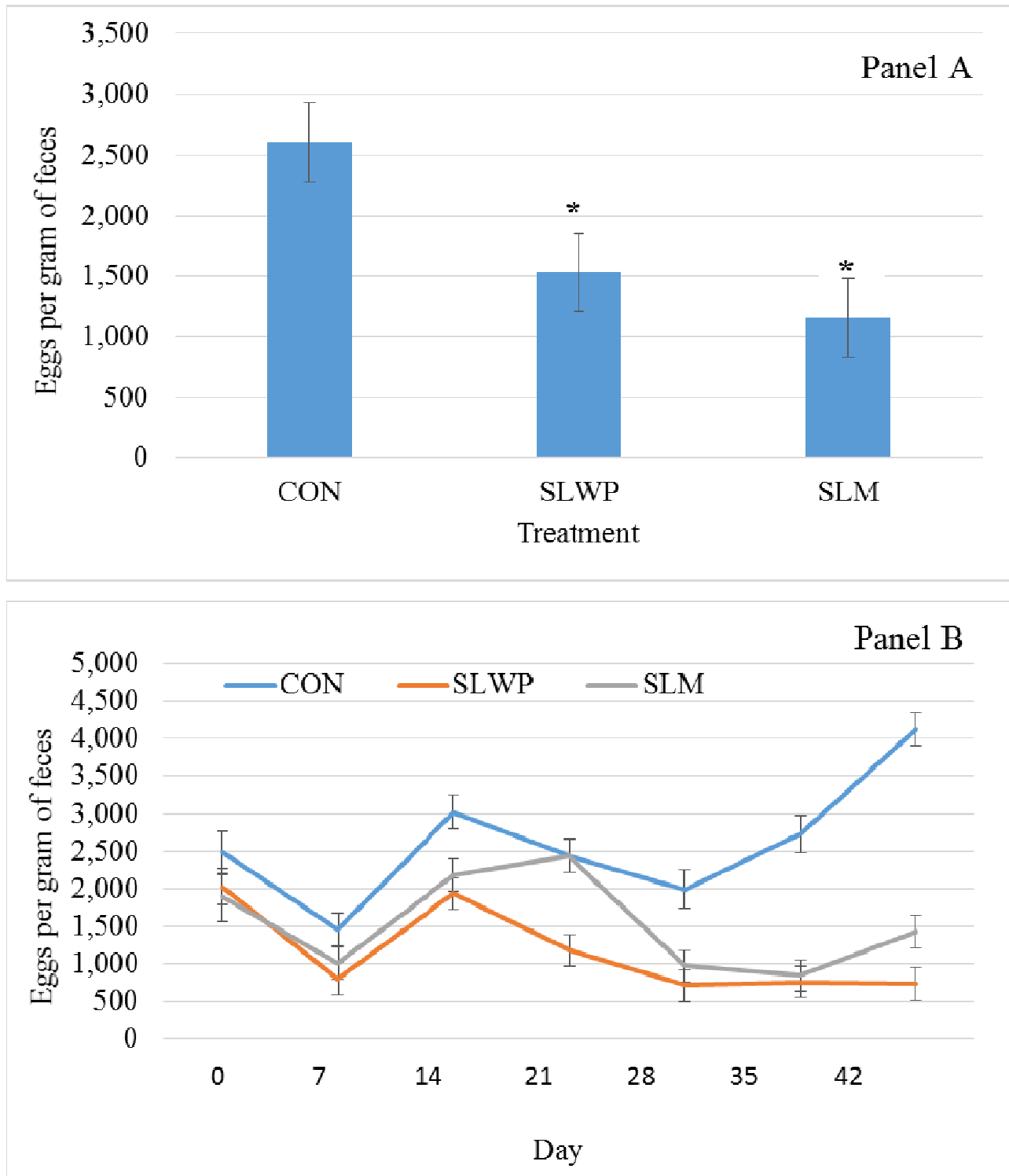

Fig. 1 Fecal egg count (FEC) (eggs per gram of feces) for goats fed sericea lespedeza leaf meal (SLM) or whole plant (SLWP) pellets compared to a commercial control (CON) pellet at $\mathbf{5 0 \%}$ of a complete ration for $\mathbf{4 2} \mathbf{d}$.

Effect of treatment, $p<0.01$, Panel A; columns with a * differ from CON, $p<0.01$ for SLM and $p=0.0564$ (tendency) for SLWP. Panel B for visual appraisal only.

Compared to Day 0, leaf meal feeding was effective faster, reducing FEC $(p<0.01)$ at Days 7, 21 (tendency, $p<0.08$ ), 28, 35 and 42, while whole plant meal fed goat FEC was only reduced $(p<0.05)$ at Days 35 and 42. There were no differences in FEC of goats fed either SL ration on Days 0, 7, 14, 21 and 42, but the SLM treatment animals had lower $(p<0.05)$ FEC than whole plant SL meal fed goats on Days 28 and 35 (Fig. 3).

\subsubsection{PCV}

There was an effect of day $(p<0.001)$ on percentage $\mathrm{PCV}$, with each time point varying from Day 0, $p<0.05$ except Day 21 ( $p=0.0512$ ) (Fig. 4). There was no effect of treatment on PCV values.

\subsubsection{Adult Worm Number}

There was no treatment effect on adult worm numbers (Table 1 ), with $H$. contortus only making up $39 \% \pm 8 \%$ of the total. 


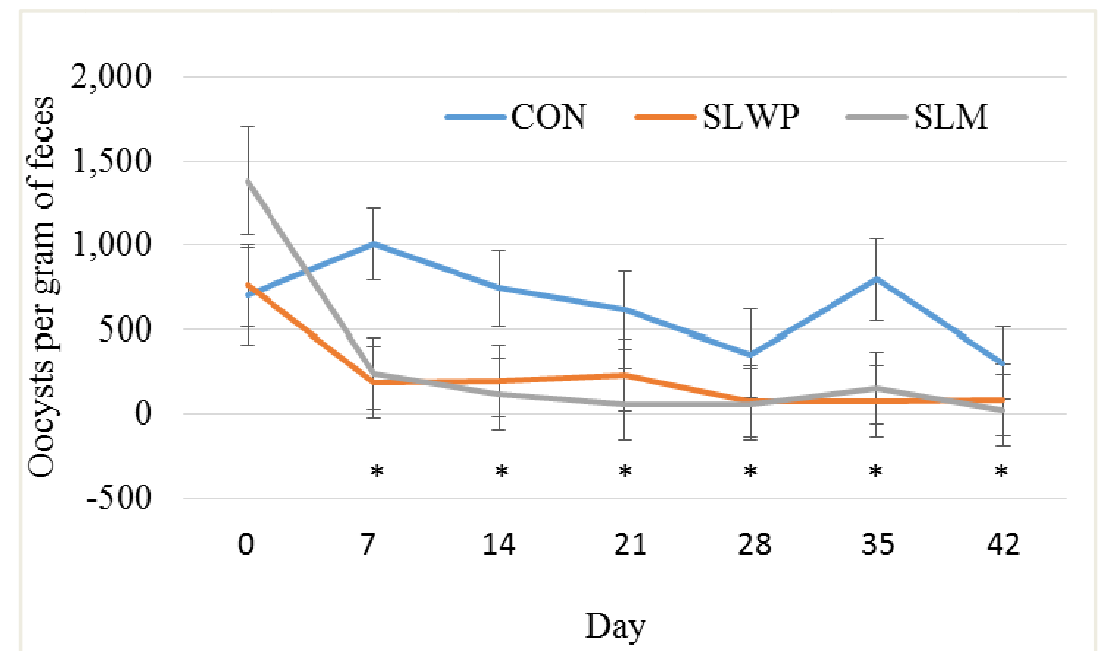

Fig. 2 Fecal oocyst count (FOC) (oocysts per gram of feces) for goats fed SLM, SLWP or a CON pellet at $50 \%$ of the diet for 42 d.

Compared to Day 0, points with * differ $p<0.01$. Treatment by day interaction, $p<0.02$.

Table 2 Haemonchus contortus, Trichostrongylus axei or Teladorsagia circumcincta along with total abomasal gastrointestinal nematode (GIN) counts for goats fed 50\% SLM or SLWP pellets compared to a commercial feed pellet (control) (Trial 1) or SLM or SLWP (Trial 2) for $42 \mathrm{~d}$.

\begin{tabular}{llllll}
\hline \multirow{2}{*}{ Trial 1} & $\begin{array}{l}\text { H. contortus } \\
\text { Female }\end{array}$ & $\begin{array}{l}\text { H. contortus } \\
\text { Male }\end{array}$ & $\begin{array}{l}\text { T. axei } \\
\text { Female }\end{array}$ & $\begin{array}{l}\text { T. axei } \\
\text { Male }\end{array}$ & \multirow{2}{*}{ Total } \\
\hline Control & $700 \pm 243$ & $344 \pm 150$ & $88 \pm 45$ & $63 \pm 29$ & $1,194 \pm 400$ \\
SLM & $483 \pm 280$ & $442 \pm 173$ & $33 \pm 52$ & $33 \pm 33$ & $992 \pm 461$ \\
SLWP & $736 \pm 259$ & $179 \pm 160$ & $143 \pm 48$ & $86 \pm 31$ & $1,443 \pm 427$ \\
\hline \multirow{2}{*}{ Trial 2} & H. contortus & H. contortus & T. circumcincta & T. circumcincta & Total \\
SLM & Female & Male & Female & Male & $696 \pm 274$ \\
SLWP & $114 \pm 40$ & $138 \pm 43$ & $258 \pm 137$ & $186 \pm 105$ & $706 \pm 292$ \\
\hline
\end{tabular}

No statistical differences were found among treatments.

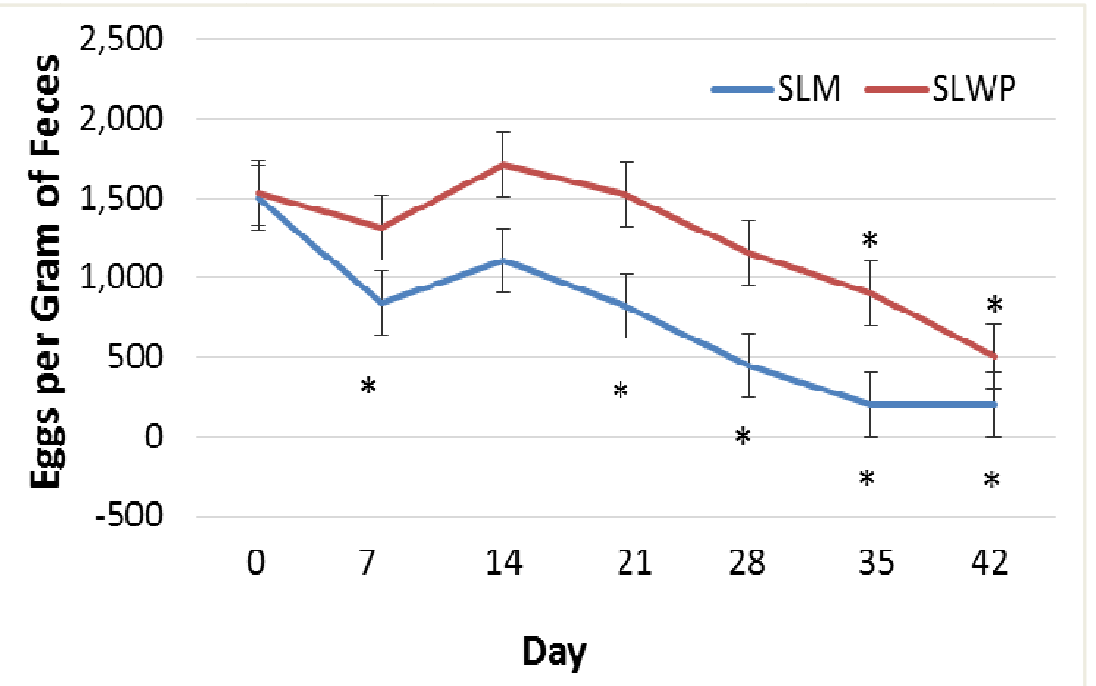

Fig. 3 FEC (eggs per gram of feces) for goats fed SLM or SLWP pellets for $42 \mathrm{~d}$ were impacted by a treatment by day interaction $(\boldsymbol{p}<\mathbf{0 . 0 0 7})$.

Points with * differ from Day 0, $p<0.01$ for SLM except for Day 21 (tendency, $p<0.08$ ) and $p<0.05$ for SLWP. 


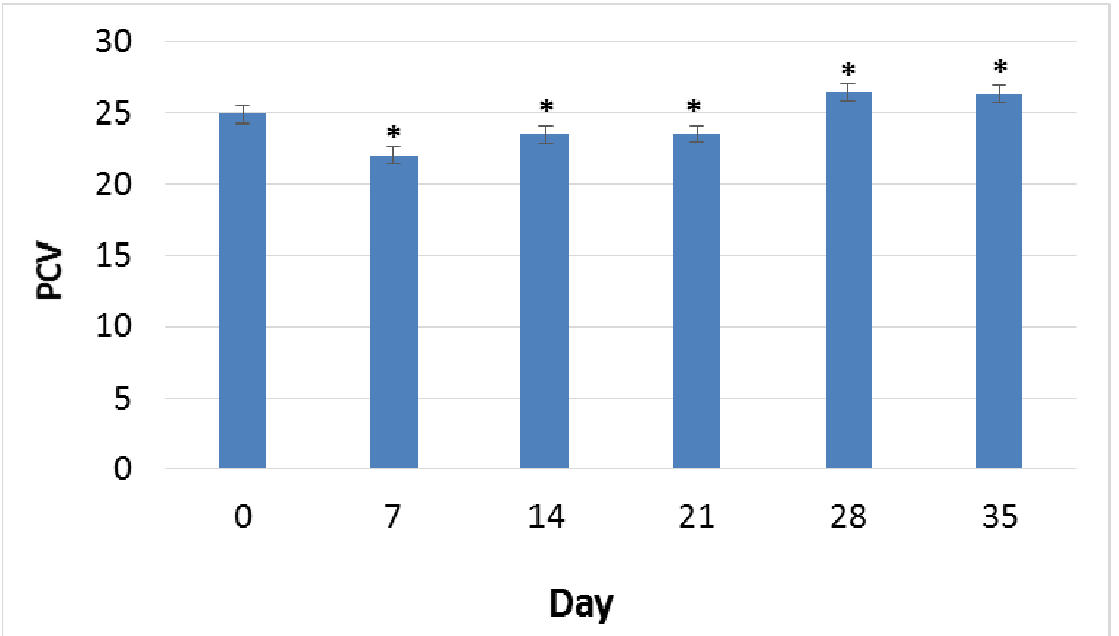

Fig. 4 Percentage packed cell volume (PCV) for goats fed SLM or SLWP pellets for $42 \mathrm{~d}$ (Day 42 PCV data not available). Compared to Day 0, all points with * varied $p<0.05$ except Day $21(p=0.0512)$; effect of day $(p<0.001)$.

\section{Discussion}

Sericea lespedeza was effective in reducing indicators of parasitic infection in goats in this investigation whether fed as the whole plant (leaves and stems) or leaf only, at different concentrations in the diet (Trial 1, 50\%; Trial 2, 25\%), or in different forms (Trial 1, pellets; Trial 2, meal). This confirms previous studies with this plant when included in the diet of sheep and goats in fresh (grazed) [29, 30], dried [26] and ensiled [37] forms for control of $H$. contortus [38] and Eimeria spp. [24, 25].

In most of the previous experiments with SL in dried forms, the treatment forages were fed at $75 \%$ of the diet or higher. Shaik et al. [26] reported 80\% reduction in FEC in young goats fed a diet of whole (leaf + stem) "AU Grazer" SL hay compared with Bermudagrass hay $(75 \%$ of the ration $+25 \%$ supplement) in a 6-week feeding trial. The goats fed the SL hay ration also had significantly higher blood PCV and lower adult worm numbers, with reductions of $70 \%$ for $H$. contortus, $26 \%$ for $T$. colubriformis and $40 \%$ for Telodorsagia circumcincta [26]. A similar study was completed with sheep fed unground SL hay and Bermudagrass (Cynodon dactylon (L.) Pers.) hay diets at approximately $80 \%$ of the diet to determine effects on establishment of GIN larvae, as well as on established infections in sheep [27]. Animals fed the
SL diet had 67\%-98\% lower FEC, 67\% fewer adult worms, and $26 \%$ less establishment of incoming larvae than the sheep on the control diet [27]. In a study comparing pelleted whole plant SL, ground SL hay, and ground Bermudagrass hay diets (75\% hay, $25 \%$ concentrate) in a 6-week feeding trial with goats, pelleting increased the percentage of total CT bound to protein in the SL material, but did not reduce its bioactivity against GIN [28]. Both the pelleted and ground SL diets reduced goat FEC compared to the control diet, with the lowest values for the kids given the SL pellets [33].

There have been relatively few previous studies with SL fed as 50\% of the diet or less. Terrill et al. [39] reported on a trial in which yearling bucks were offered one of four diets consisting of $75 \%$ hay and $25 \%$ concentrate, with the hay portion of each diet being a combination of ground whole plant SL $(0 \%$, 25\%, 50\% and 75\%) and Bermudagrass (C. dactylon (L.) Pers.; 75\%, 50\%, 25\% and 0\%), providing total dietary SL levels of $56.3 \%, 37.5 \%, 18.8 \%$ and $0 \%$, respectively. There were significant reductions in FEC of goats on the $56.3 \%$ and $37.5 \%$ whole plant SL rations, but no effect at the $18.8 \%$ level [39], while kids on the $56.3 \%$ SL diet had significantly reduced abomasal worm burdens. Goats on the 56.3\% SL diet also tended to have higher PCV values than control animals, while PCV values and adult worm numbers 
of the kids on the $37.5 \%$ and $18.8 \%$ SL rations were not different from controls [39]. In the current investigation, although both leaf only and whole plant SL were effective at reducing GIN egg counts in goat feces, the leaf only ration was more effective than the whole plant ration when fed at $25 \%$ of the diet (Fig. 3; Trial 2). In contrast, similar effects (reductions) were seen for GIN and Eimeria spp. oocyst counts relative to the control diet when whole plant and leaf only SL were fed at $50 \%$ of the diet (Trial 1). This is an important consideration for feed manufacturers interested in pelleting SL, as separating SL leaves from the stems and then processing them into pellets adds to the cost of production, increasing final costs to consumers (farmers).

Results of this study suggest that feeding SL at $25 \%$ of the diet may effectively express the anti-parasitic bioactivity of this plant when using only leaf material, while whole plant SL can be effectively used at 50\% of the diet. The whole plant and leaf only SL pellets used in Trial 1 were only 90\% SL in addition to other ingredients, such as molasses, so the actual dietary level of SL for each pellet was $45 \%$. These results support the findings of Terrill et al. [39], in which ground whole plant SL effectively reduced FEC in goats when fed at $37.5 \%$ of the diet, but not at $18.8 \%$. The question of how much dietary SL is required to reduce worm burdens in animals needs further study. None of the levels or forms of SL fed in the current investigation reduced adult GIN numbers.

Although not determined in the current investigation, including SL whole plant or leaf only meal or pellets in the diet of domestic or wild ruminant animals would also have nutritional consequences, likely due to differences in leaf and stem CP levels and CT concentration and structure. Mechineni et al. [29] reported much higher CT in SL leaves than stems (16.0 g vs. $3.3 \mathrm{~g} / 100 \mathrm{~g}$ dry weight), a slightly higher percentage of prodelphinidin-type tannins (98\% vs. 94\%, respectively) and polymers of larger mean degrees of polymerization (42 vs. 18, respectively). Other reports on SL also showed higher concentration of CP and CT in SL leaves than stems for both high- and low-tannin SL cultivars, but protein concentration and digestibility were negatively associated with CT level [34]. Additional research is needed to determine the optimal level of leaf and stem SL in the diet of ruminants from a nutritional standpoint while maintaining an effective level of bioactivity.

\section{Conclusions}

SLWP and SLM pellets were both bioactive against GIN and Eimeria spp. in goats when fed at $50 \%$ of the diet. When fed at $25 \%$ of the diet, SLM pellets reduced FEC more quickly and were more effective overall against GIN infection, likely due to its higher concentration of CT. This information may be of interest to both feed manufacturers and farmers interested in the production and utilization of SL as a nutraceutical feedstuff for livestock.

\section{Acknowledgments}

This material is based upon work that is supported by the National Institute of Food and Agriculture, U.S. Department of Agriculture, under award numbers 2011-33610-30836 and 2010-51300-21641.

\section{References}

[1] Sykes, A. R. 1994. "Parasitism and Production in Farm Animals.” Anim. Prod. 59 (2): 155-72.

[2] Hoste, H., Martinez-Ortiz-De-Montellano, C., Manolaraki, F., Brunet, S., Ojeda-Robertos, N., Fourquaux, I., Torres-Acosta, J. F., and Sandoval-Castro, C. A. 2012. "Direct and Indirect Effects of Bioactive Tannin-Rich Tropical and Temperate Legumes against Nematode Infections.” Vet. Parasitol. 186 (1-2): 18-27.

[3] Waller, P. J. 1997. "Sustainable Helminth Control of Ruminants in Developing Countries.” Vet. Parasitol. 71 (2-3): 195-207.

[4] O’Brien, D. 2017. "The Impact of Parasite Infections on Small Ruminant Productivity.” Presented at Am. Consort. Small Rumin. Parasit. Cont. Timely Topic, May, 2017.

[5] Miller, J. E. 1996. "Controlling Goat Parasites in the Southeast.” In Proc. Southeast Reg. Meat Goat Prod. Sym., 21-24 February, 1996, Florida A\&M University, 

Gastrointestinal Nematode and Coccidial Infection in Goats

Tallahassee, FL, 80-2.

[6] Kaplan, R. M., and Vidyashankar, A. N. 2012. “An Inconvenient Truth: Global Worming and Anthelmintic Resistance.” Vet. Parasitol. 186 (1-2): 70-8.

[7] Papadopoulos, E., Gallidis, E., and Ptochos, S. 2012. "Anthelmintic Resistance in Sheep in Europe: A Selected Review.” Vet. Parasitol. 189 (1): 85-8.

[8] Hammond, J. A., Fielding, D., and Bishop, S. C. 1997. "Prospects for Plant Anthelmintics in Tropical Veterinary Medicine.” Vet. Res. Comm. 21: 213-28.

[9] Bowman, D. D. 2014. Georgis' Parasitology for Veterinarians. Elsevier Health Sciences.

[10] Greif, G., Stephan, B., and Haberkorn, A. 1996. "Intraspecific Polymorphisms of Eimeria Species due to Resistance due to Coccidial Drugs.” Parasitol. Res. 82: 706-14.

[11] Haberkorn, A. 1996. "Chemotherapy of Human and Animal Coccidiosis: State and Perspectives.” Parasitol. Res. 82: 193-9.

[12] Kaplan, R. M. 2004. "Drug Resistance in Nematodes of Veterinary Importance: A Status Report.” Trends Parasitol. 20 (10): 477-81.

[13] Terrill, T. H., Miller, J. E., Burke, J. M., Mosjidis, J. A., and Kaplan, R. M. 2012. "Experiences with Integrated Concepts for the Control of Haemonchus contortus in Sheep and Goats in the United States.” Vet. Parasitol. 186 (1-2): 28-37.

[14] Niezen, J. H., Waghorn, T. S., Charleston, W. A. G., and Waghorn, G. C. 1995. "Growth and Gastrointestinal Nematode Parasitism in Lambs Grazing either Lucerne (Medicago sativa) or Sulla (Hedysarum coronarium) Which Contains Condensed Tannins.” J. Agric. Sci. 125 (2): 281-9.

[15] Niezen, J. H., Charleston, W. A. G., Robertson, H. A., Shelton, D., Waghorn, G. C., and Green, R. 2002. "The Effect of Feeding Sulla (Hedysarum coronarium) or Lucerne (Medicago sativa) on Lamb Parasite Burdens and Development of Immunity to Gastrointestinal Nematodes.” Vet. Parasitol. 105 (3): 229-45.

[16] Molan, A. L., Meagher, L. P., Spencer, P. A., and Sivakumaran, S. 2003. "Effect of Flavon-3-ols on in Vitro Egg Hatching Larval Development and Viability of Infective Larvae of Trichostrongylus colubriformis." Int. J. Parasitol. 33 (14): 1691-8.

[17] Paolini, V., De la Farge, F., Prevot, F., Dorchies, P., and Hoste, H. 2005. "Effects of the Repeated Distribution of Sainfoin Hay on the Resistance and the Resilience of Goats Naturally Infected with Gastrointestinal Nematodes.” Vet. Parasitol. 127 (3-4): 277-83.

[18] Hoveland, C. S., Windham, W. R., Boggs, D. L., Durham, R. G., Calvert, G. V., Newsome, J. F., Dobson Jr., J. W., and Owsley, M. 1990. "Sericea Production in Georgia.
Research Bulletin 393.” The Georgia Agricultural Experiment Stations, College of Agriculture, the University of Georgia.

[19] Mosjidis, J. A., and Terrill, T. H. 2013. "Sericea Lespedeza." In Proceedings of the American Consortium for Small Ruminant Parasite Control 10th Anniversary Conference, May 20-22, 2013, Fort Valley, GA, 49-52.

[20] Puchala, R., Min, B. R., Goetsch, A. L., and Sahlu, T. 2005. "The Effect of a Condensed Tannin-Containing Forage on Methane Emission by Goats.” J. Anim. Sci. 83 (1): 182-6.

[21] Naumann, H. D., Tedeschi, L. O., Muir, J. P., Lambert, B. D., and Kothmann, M. M. 2013. "Effect of Molecular Weight of Condensed Tannins from Warm-Season Perennial Legumes on Ruminal Methane Production in Vitro.” Biochem. Syst. Ecol. 50: 154-62.

[22] Messman, M. A., Weiss, W. P., and Albrecht, K. A. 1996. "In Situ Disappearance of Individual Proteins and Nitrogen from Legume Forages Containing Varying Amounts of Tannins.” J. Dairy Sci. 79 (8): 1430-5.

[23] Littlefield, K. A., Muir, J. P., Lambert, B. D., and Tomberlin, J. K. 2011. "Condensed Tannins Inhibit House Fly (Diptera: Muscidae) Development in Livestock Manure.” Environ. Entomol. 40 (6): 1572-6.

[24] Burke, J. M., Miller, J. E., Terrill, T. H., Orlik, S. T., Acharya, M., Garza, J. J., and Mosjidis, J. A. 2013. "Sericea Lespdeza as an Aid in the Control of Eimeria spp. in Lambs.” Vet. Parasitol. 193 (1-3): 39-46.

[25] Kommuru, D. S., Barker, T., Desai, S., Burke, J. M., Ramsay, A., Mueller-Harvey, I., Kamisetti, N., and Terrill, T. H. 2014. "Use of Pelleted Sericea Lespedeza (Lespedeza cuneata) for Natural Control of Coccidia and Gastrointestinal Nematodes in Weaned Goats.” Vet. Parasitol. 204 (3-4): 191-8.

[26] Shaik, S. A., Terrill, T. H., Miller, J. E., Kouakou, B., Kannan, G., Kaplan, R. M., Burke, J. M., and Mosjidis, J. A. 2006. "Sericea Lespedeza Hay as a Natural Deworming Agent against Gastrointestinal Nematode Infection in Goats.” Vet. Parasitol. 139 (1-3): 150-7.

[27] Lange, K., Olcott, D. D., Miller, J. E., Mosjidis, J. A., Terrill, T. H., Burke, J. M., and Kearney, M. T. 2006. "Effect of Sericea Lespedeza (Lespedeza cuneata) Fed as Hay, on Natural and Experimental Haemonchus contortus Infections in Lambs.” Vet. Parasitol. 141 (3-4): 273-8.

[28] Terrill, T. H., Mosjidis, J. A., Moore, D. A., Shaik, S. A., Miller, J. E., Burke, J. M., Muir, J. P., and Wolfe, R. 2007. "Effect of Pelleting on Efficacy of Sericea Lespedeza Hay as a Natural Dewormer in Goats.” Vet. Parasitol. 146 (1-2): 117-22.

[29] Mechineni, A., Kommuru, D. S., Gujja, S., Mosjidis, J. A., Miller, J. E., Burke, J. M., Ramsay, A., 
Mueller-Harvey, I., Kannan, G., Lee, J. H., Kouakou, B., and Terrill, T. H. 2014. "Effect of Fall-Grazed Sericea Lespedeza (Lespedeza cuneata) on Gastrointestinal Nematode Infections of Growing Goats.” Vet. Parasitol. 204 (3-4): 221-8.

[30] Burke, J. M., Miller, J. E., Mosjidis, J. A., and Terrill, T. H. 2012. "Grazing Sericea Lespedeza for Control of Gastrointestinal Nematodes in Lambs.” Vet. Parasitol. 186 (3-4): 507-12.

[31] Burke, J. M., Whitley, N. C., Pollard, D. A., Miller, J. E., Terrill, T. H., Moulton, K. E., and Mosjidis, J. A. 2011. "Dose Titration of Sericea Lespedeza Leaf Meal on Haemonchus contortus Infection in Lambs and Kids.” Vet. Parasitol. 27 (2-4): 345-9.

[32] Joshi, B. R., Kommuru, D. S., Terrill, T. H., Mosjidis, J. A., Burke, J. M., Shakya, K. P., and Miller, J. E. 2011. "Effect of Feeding Sericea Lespedeza Leaf Meal in Goats Experimentally Infected with Haemonchus contortus.” Vet. Parasitol. 178 (1-2): 192-7.

[33] Gujja, S., Terrill, T. H., Mosjidis, J. A., Miller, J. E., Mechineni, A., Kommuru, D. S., Shaik, S. A., Lambert, B. D., Cherry, N. M., and Burke, J. M. 2013. "Effect of Supplemental Sericea Lespedeza Leaf Meal Pellets on Gastrointestinal Nematode Infection in Grazing Goats.” Vet. Parasitol. 191 (1-2): 51-8.
[34] Donnelly, E. D., and Anthony, W. B. 1973. "Relationship of Sericea Lespedeza Leaf and Stem Tannin to Forage Quality.” Agron. J. 65 (6): 993-4.

[35] Whitlock, H. V. 1948. "Some Modifications of the McMaster Helminth Egg Counting Technique Apparatus.” J. Coun. Sci. Ind. Res. 21 (3): 177-80.

[36] SAS Institute. 2016. SAS/STAT Software: Changes and Enhancements. Release 9.2, SAS Technical Report, SAS Institute, Cary, NC.

[37] Terrill, T. H., Griffin, E., Kommuru, D. S., Miller, J. E., Mosjidis, J. M., Kearney, J. E., and Burke, J. M. 2016. "Effect of Ensiling on Anti-parasitic Properties of Sericea Lespedeza.” In Proc. AFGC Annual Meeting, January 10-13, 2016, Baton Rouge, LA.

[38] Kommuru, D. S., Whitley, N. C., Miller, J. E., Mosjidis, J. A., Burke, J. M., Gujja, S., Mechineni, A., and Terrill, T. H. 2015. "Effect of Sericea Lespedeza Leaf Meal Pellets on Adult Female Haemonchus contortus in Goats." Vet. Parasitol. 207 (1-2): 170-5.

[39] Terrill, T. H., Dykes, G. S., Shaik, S. A., Miller, J. E., Kouakou, B., Kannan, G., Burke, J. M., and Mosjidis, J. A. 2009. "Efficacy of Sericea Lespedeza Hay as a Natural Dewormer in Goats: Dose Titration Study." Vet. Parasitol. 163 (1-2): 52-6. 